\title{
"APEIRON" DE CAIO FERNANDO ABREU: A ARTE MODERNA ENTRE O ARCAICO E O ANTIGO
}

\author{
Érica de Cássia Modesto Coutrim*
}

\begin{abstract}
RESUMO: O presente ensaio traça algumas reflexões sobre a situação do sujeito e da arte na modernidade. Partindo de teorias de Walter Benjamin e Theodor Adorno, é feita uma interpretação do conto "Apeiron", publicado em pleno período ditatorial brasileiro, ou seja, numa época impregnada de barbárie e dominação que, segundo os filósofos supramencionados, fizeram com que a arte que intui representar um mundo em estado de caos, por um sujeito perplexo, ou está em conjunção com o sistema, ou é alienado, deixando de ter sentido na modernidade. Abreu constrói um conto que não apresenta soluções. Polissêmico e alegórico em sua essência, "Apeiron" provoca dúvida e reflexão, concordando assim com o conceito de arte moderna dos filósofos da Escola de Frankfurt.
\end{abstract}

PALAVRAS-CHAVE: Violência - Modernidade - Caio Fernando Abreu

ZUSAMMENFASSUNG: Dieser Essay über einen Text von Caio Fernando Abreu stellt einigen Reflexionen über die Situation des Subjektes und der Kunst in der Modernität. Mit Adorno und Benjaminstheorien macht man eine Interpretation der Kurzerzählung „Apeiron“, herausgegeben während der diktatorischen Periode in Brasilien, das heißt, während einer Epoche mit Gewalt und Beherrschung. Laut die Philosophen oben zitiertert, die Kunst, die eine chaotische Welt mit einem bestürzten Subjekt repräsentiert, entweder verbundet mit dem System ist oder geisteskrank ist, dann hat sie keinen Sinn in der Modernität. Der ,,gaúcho" Schriftsteller macht eine Kurzerzählung, die keine Lösung findet. Vieldeutig und sinnbildlich in seiner Essenz, provoziert „,Apeiron “Zweifel und Reflexion, dann ist die Erzählung einverstanden mit dem modernen Kunstkonzept von Walter Benjamin und Theodor Adorno.

PALAVRAS-CHAVE: Gewalt-Modernität-Caio Fernando Abreu

"Apeiron", o título do conto sobre o qual farei algumas reflexões, é um conceito criado pelo filósofo grego Anaximandro (610 e 547 a.C.), cujo sentido, devido à ausência de registros específicos, só pode ser definido pela interpretação de filósofos posteriores a ele. Platão, por exemplo, entende o apeiron como o princípio organizador de um mundo surgido do caos, enquanto Aristóteles o compreende como o "infinito", o "ilimitado".

Assim como o termo de Anaximandro, que assumiu interpretações particulares de acordo com os pensadores e contextos envolvidos, o conto de Caio Fernando Abreu, publicado em 1970, não admite uma leitura com um sentido único e determinado.

Correndo o risco de cometer uma arbitrariedade, assumirei, nesta análise, a interpretação platônica, mas de modo antagônico, ou seja, entendo que o conto se opõe ao princípio do apeiron ao se recusar à reorganização de um mundo que se encontraria novamente em estado caótico. Mundo este entendido aqui como a modernidade, ou mais especificamente, a sociedade e a arte brasileiras do período ditatorial.

\footnotetext{
* Pós-graduanda do departamento de Literatura alemã da Universidade de São Paulo (USP), ericacoutrim@yahoo.com.br.
} 
O "Inventário da morte" (contendo "Apeiron" e outros sete contos), primeira parte que compõe o livro "Inventário do irremediável" de Caio Fernando Abreu, é introduzido pelos perturbadores versos de Álvaro de Campos, assumindo também a modernidade como seu espaço e tema.

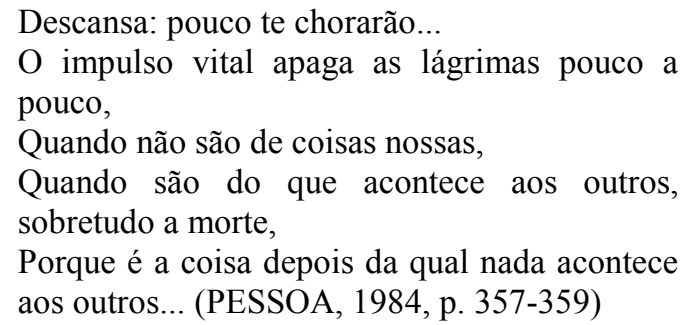

Perplexo diante de relações e representações falsas, da incapacidade de autoconhecimento do sujeito e da ausência do sentido na existência e no mundo, o heterônimo pessoano aponta a morte como a única possibilidade de conhecimento, assim como "Apeiron" a sugere como única forma de plenitude de constituição do indivíduo na modernidade e/ou no Brasil como nação moderna, mas fundamentada pelo atraso e pela violência, ou nas palavras de Roberto Schwarz "em razões de ser antagônicas" (2000, p. 40).

O conto é narrado em terceira pessoa, mas de um modo tão intimista que chega a confundir as percepções de narrador e personagem. São apresentadas as reações do único personagem diante de sua imagem refletida num espelho: perplexidade, descoberta da fragmentariedade e estranhamento que lembram a situação da criança no período denominado por Lacan como "estádio do espelho". Assim como a criança, o sujeito se choca diante de sua imagem (de uma representação) que apresenta uma totalidade que ele não é capaz de encontrar em seu próprio corpo, ou seja, fazendo com que o imaginário apresente uma completude de sentido incoerente com a realidade.

Enquanto a criança nota sua imaturidade corpórea diante do espelho e se sente fragilizada por encontrar no outro (na imagem) uma forma de plenitude, o personagem não encontra na representação especular as marcas da barbárie da modernidade, ou mais especificamente, do processo de modernização contraditório e violento da sociedade brasileira potencializado pela ditadura, ou seja, "a maldade, a violência, a frieza, o cálculo, o cinismo, a agressão" (ABREU, 1970, p. 21), que julga que deveriam estar marcadas em cada detalhe de seu corpo e de sua memória.

Tal percepção lembra o conto $O$ espelho de Guimarães Rosa, visto que lá o personagem, num "processo lento", apaga a imagem monstruosa que o espelho um dia lhe oferecera. $\mathrm{O}$ espanto provocado pela ausência do reflexo perdido pelo personagem de Rosa é semelhante ao choque que se nota em "Apeiron" diante da ausência de marcas que deveriam ter sido deixadas pela existência. No entanto, em "O espelho", a experiência traz de volta uma ínfima parcela da "alma" do personagem, enquanto no conto de Caio Fernando Abreu, sequer sentimentos intensos ou melancolia, "aquele estar-debruçado-na-sacada-num-fim-de-tarde" (ABREU, 1970, p. 22) foram capazes de dar alguma esperança de plenitude àquele sujeito, ou seja, "já não era uma reorganização, não era sequer um processo: estava consumado e além, muito além de qualquer coisa" (ibid., p. 22).

Assim, o personagem se questiona quanto à possibilidade de ter voltado a "um estágio anterior" (ibid., p. 22), ou seja, de sentir o mesmo mal-estar ao perceber que a imagem que vê refletida apresenta uma unidade impossível à sua real situação. Segundo 
Maria Lucia Santaella Braga (1999), a reação provocada pelo estádio do espelho seria como uma "metáfora da condição humana", em que o indivíduo tem a percepção de um sentido que falta à sua existência.

Do ponto de vista de Adorno, o conto pode aludir ao dilema entre o fragmentário e a síntese, questionando a idéia da representação como conhecimento da verdade, contrariando assim o cartesianismo e assumindo a metáfora e a polissemia em sua essência.

"Apeiron" não permite uma "leitura confortável" como aquelas em que conseguimos dizer que chegamos a uma conclusão ou que entendemos a moral da história. O conto é pautado pela pluralidade de perspectivas, o que aponta para uma posição contrária ao discurso autoritário. Por isso, é preciso explicitar que o que será exposto nestas linhas diz respeito tão somente a uma leitura que indica provisoriedade e individualidade de interpretações para cada leitor.

Ainda numa perspectiva adorniana, poderíamos considerar duas hipóteses iniciais de interpretação. A primeira sugere que o conto trata da situação social brasileira no período ditatorial, que intentava sustentar o poder por meio da reificação, ou seja, por meio da difusão de um pensamento uno afirmado pela violência como princípio de ordem. Ainda neste sentido, trata também da dificuldade de que alguém se constitua plenamente como sujeito diante da situação na qual o Brasil vinha se fundamentando enquanto sociedade burguesa sustentada pela escravidão, pela miséria, pela cassação de direitos civis e, conseqüentemente, pela impossibilidade de plenitude existencial. A segunda hipótese (vinculada à primeira) remete a uma discussão do papel da obra de arte na modernidade, ou seja, representação, tendência política e literária (de acordo com Walter Benjamin) e de imanência da história da arte conforme afirma Adorno.

Questionando o valor de verdade na representação, ao colocar o conflito entre o sujeito e sua percepção a respeito de si mesmo, o conto, fundamentado numa indeterminação perturbadora, assume um caráter alegórico que, segundo Gagnebin em $A$ propósito do conceito de crítica em Walter Benjamin, visa causar choque e estranhamento no leitor, levando-o assim à reflexão sobre a realidade.

Creio que o conto apresenta, por um lado, uma perspectiva de crítica ao papel da arte e, por outro, um questionamento ao modelo ilusório de progresso e ordem na modernidade e na democracia institucional. No entanto, nenhum dos tópicos está, em hipótese alguma, desvinculado do outro. $\mathrm{O}$ autor admite a cifra em "Apeiron" a fim de que, segundo Adorno em Teoria estética, o social não se encontre na imitação ou na comunicação direta com a sociedade, mas sim de forma mediatizada para que o leitor, perplexo, busque o conhecimento.

A narrativa discutiria, então, uma frustração do sujeito diante da percepção de sua incapacidade de alcançar a totalidade enquanto indivíduo, além do questionamento da obra de arte que procura representar o sujeito e o mundo com um sentido inexistente e impossível à sua condição humana no século $\mathrm{XX}$, contrariando assim o pensamento e a arte tradicionais de caráter burguês, que "caminham de mãos dadas" com o autoritarismo, tornando-se mercadorias.

A ausência de síntese, no entanto, não se restringe ao personagem, o leitor é também colocado numa situação de impasse afirmada pela grande quantidade de interrogações no texto. Segundo Adorno (1982), as contradições e a falta de sentido na obra de arte são causadas, não só na temática, mas também na forma, pelos conflitos 
sociais e os antagonismos não resolvidos na realidade do momento em que a obra está inserida.

A fragmentação aparece por todos os lados e provoca a sensação de que ela é o próprio espaço de "Apeiron". A desordem começa na temporalidade que apresenta um conflito entre o passado em que a narrativa se dá e o período que é anterior a ele, oscilando entre o pretérito mais-que-perfeito e o imperfeito.

Poderíamos, então, entender estes diferentes momentos, diante do conflito entre personagem e imagem refletida no espelho, como um questionamento de modelos artísticos como o romantismo e o realismo, que apontavam para a maturação e síntese do sujeito e de sua conformidade com o mundo.

Em Teoria estética, Adorno traça uma crítica à arte que, diante dos efeitos catastróficos da modernidade, ainda se propõe à mentira da representação (cf. ADORNO, 1982, p. 272), afirmando um sentido inexistente ao sujeito e ao mundo, pautado pelo detalhamento da superfície, e assim auxiliando na produção do engodo.

Ao tentar encontrar alguma experiência, algum entendimento a respeito de si, num processo frustrado, o personagem se dirige ao detalhamento meticuloso de seus traços físicos e, até mesmo, a sentimentos intensos. Tal busca, no entanto, ao invés de levá-lo à maturação, encaminha-o à supressão.

Ao recusar e se chocar com a representação mimética em sua temática, admitindo a polissemia e a alegoria de caráter benjaminiano como instrumentos de produção de conhecimento, o conto questiona o valor da arte que se abstrai da situação de violência na qual a sociedade burguesa vinha se constituindo e, assim, relegando a uma condição de barbárie a maioria da população brasileira. Abstração esta que faz da arte uma mercadoria e do homem conformado com sua situação na modernidade instrumentos de uma "limpeza impossível e inútil" (ABREU, p. 21).

Diante de seu reflexo, o personagem se questiona quanto à possibilidade de se ter voltado a um estágio anterior ou ainda ao retorno de "o que dá conselhos" (ibid., p. 21). Tais citações podem ser relacionadas às reflexões de Walter Benjamin em "O narrador" (1980), em que discute a perda da capacidade de narrar, isto é, de intercambiar experiências. Tal impossibilidade, comum em estágios anteriores, teria sido propiciada pelos efeitos da modernidade e pela barbárie, fazendo com que "a sensação de se sentar e ler um bom livro" (BENJAMIN, 1996, p. 206) tenha se tornado antiga para Benjamin e arcaica para Adorno.

De modo semelhante, a sensação de se ter "campinas verdes pelo cérebro $e$ colinas suaves e palmeiras esguias e um cor de rosa encobrindo um lago azul no coração" (ABREU, p. 22) teria se tornado incoerente para a nossa sociedade e para o nosso tempo. A impossibilidade de experiência de valor benjaminiano, para o personagem, torna-se mais evidente nas linhas finais da narrativa, em que ele, diante de várias tentativas frustradas de compreensão, ao se dar conta de seu estado absurdo, "tenta", pela primeira e única vez, tomar a voz na narrativa "Meu Deus, isso é horrível, é horrível! Quis gritar!” (ibid., p. 22). Tal tentativa é, no entanto, frustrada, já era tarde demais e seu fim tornava-se inevitável.

O final trágico e desconfortável do conto contraria a tradicional idéia de que a arte deva caminhar para uma solução. "Apeiron" caminha para a percepção do personagem quanto ao seu estado precário e sem esperanças de plenitude.

"Apeiron", em sua essência, repudia o autoritarismo e, principalmente, traça uma crítica à arte e aos artistas que se abstraem do mundo e fazem de suas obras representações ilusórias de um mundo e de um homem que já não existem. 
Deste modo, podemos inferir que, neste conto, há, pelo menos como uma das hipóteses interpretativas, uma crítica à mímesis ou à totalização que são, segundo Adorno e Horkheimer em Dialética do esclarecimento, instrumentos utilizados para encobrir os conflitos, fazendo com que a arte se torne mercadoria ao entrar em conformidade com um sistema autoritário que produz efeitos catastróficos para $\mathrm{o}$ homem, para a história e, consequentemente, para a arte.

Desta interpretação, pode-se depreender que a arte de valor arcaico que representa um sujeito e um mundo de um modo contraditório e impossível, no que diz respeito à modernidade e à situação social brasileira, está em inconformidade com o seu tempo e com a história. Diante do conflito entre o personagem e sua imagem desenvolvido no conto, esperamos que aquela figura com uma ordem de sentido cartesiano seja suprimida - o que de fato ocorre. O que não esperamos é que também o personagem a acompanhe, impossibilitando qualquer sentido, indicação ou esperança. Pois "Apeiron", como já mencionado, recusa seu próprio conceito, isto é, não pretende empregar ordem ao caos, tampouco dar respostas. A morte surge como a única verdade, a única forma de síntese, deixando ao leitor um impasse quanto à sua existência e ao crítico quanto ao papel da obra de arte na modernidade.

\section{REFERÊNCIAS}

ABBAGRANO, Nicola. Dicionário de filosofia. São Paulo: Martins Fontes, 2000.

ABREU, Caio Fernando. Inventário do irremediável. Porto Alegre: Editora Movimento, 1970.

ADORNO, Theodor. Notas de Literatura I. São Paulo: Duas Cidades/ Editora 43, 2003. . Teoria estética. Lisboa: Edições 70, 1982.

AUDI, Robert. The Cambridge dictionary of philosophy. New York: Cambridge University Press, 1999.

BENJAMIN, Walter. A modernidade e os modernos. Rio de Janeiro: Tempo brasileiro, 1975.

- Magia e técnica, arte e política: ensaios sobre literatura e história da cultura. São Paulo: Brasiliense, 1996.

. Origem do drama barroco alemão. São Paulo: Brasiliense, 1984.

BRAGA, M. L. S. As três categorias peircianas e os três registros lacanianos. Scielo, 1999. Disponível em:. http://www.scielo.br/cgi-bin/wxis.exe/iah/. Acesso em: 08 de junho de 2005.

FERNANDES, Florestan. A ditadura em questão. São Paulo: T.A.Queiroz, 1982. . A revolução burguesa no Brasil. Rio de Janeiro: Zahar, 1981.

FIORIN, José Luiz. Introdução à lingüistica II: princípios de análise. São Paulo: Contexto, 2003.

GAGNEBIN, Jeanne-Marie. A propósito do conceito de crítica em Walter Benjamin. In: Discurso. São Paulo: FFLCH-USP, 1980.

RITTER, Joachim; GRÜNDER, Karlfried; EISLER, Rudolf. Historisches Wörterbuch der Philosophie. Basel: Schwabe, 1971.

ROSA, João Guimarães. Primeiras estórias. Rio de Janeiro: Nova Fronteira, 1985.

SCHWARZ, Roberto. Um mestre na periferia do capitalismo. São Paulo: Duas Cidades/Editora 34, 2000. 